\title{
Study to identify the role of high performance liquid chromatography in detecting haemoglobinopathies in antenatal patients
}

\author{
Komal D. Sawaimul ${ }^{1}$, M. Banyameen Iqbal ${ }^{2, *}$, Vijayalaxmi D. Sawaimul ${ }^{3}$, Tushar Kambale ${ }^{4}$, \\ Rajharsh Hanmante ${ }^{5}$
}

\begin{abstract}
${ }^{\mathbf{1}}$ Assistant Professor, ${ }^{\mathbf{2 , 4}}$ Associate Professor, Dept. of Pathology, Dr. D.Y Patil Medical College, Hospital and Research centre, Pimpri, Pune, Maharashtra, ${ }^{\mathbf{3}}$ Assistant Professor, Dept. of Orthodontics, VYWS Medical College, Amravati, Maharashtra, India, ${ }^{5}$ Assistant Professor, Dr Shankar Rao Chavan Government Medical College,
\end{abstract} Nanded, Maharashtra, India

*Corresponding Author:

Email: banzey@gmail.com

\begin{abstract}
Introduction: Haemoglobinopathy is a major genetic public health problems in India, responsible for significant morbidity and mortality. Individuals with trait (carriers) are healthy and unaware of their carrier status unless specifically screened. If a couple carry a clinically significant haemoglobinopathy trait there is a 1 in 4 chance with each pregnancy that their child will inherit a major haemoglobinopathy. The most effective approach to reduce the burden of the society is to reduce the incidence by implementation of a carrier screening programme.

Material and Methods: The present study was carried out in a tertiary care hospital for a period of 2 years. 500 Antenatal patients attending Obstetric-out patient department for routine check-up were included in the study. Screening of patient was done by Solubility test, Sickling test and Alkali denaturation test. Finally a very standardized method to detect $\mathrm{HbA}_{2}$ and $\mathrm{HbF}$ was done by using an automated High Performance Liquid Chromatography.

Results: Out of a total of 500 pregnant women $4 \%$ were having haemoglobinopathies, whereas $96 \%$ had normal haemoglobin. Out of 20 cases, maximum number of cases i.e. $2.2 \%$ was of $\beta$-Thalassemia trait, followed by Sickle cell trait cases i.e. $1.2 \%$. Other haemoglobinopathies are also found i.e. sickle cell disease $0.2 \% \delta \beta$ Thalassemia case $1.2 \%$ and double heterozygous $0.2 \%$. Out of a total of 20 positive pregnant women only partners of 8 women were screened and out of them $37.5 \%$ were found positive.

Conclusion: Detection of carrier status using HPLC during pregnancy along with couple screening provides prospective parents with the option of testing the fetus for hemoglobinopathy.
\end{abstract}

Keywords: Antenatal, Double heterozygous, Haemoglobinopathies, High Performance Liquid Chromatography, $\beta$-Thalassemia trait.

Received: $14^{\text {th }}$ July, 2017

Accepted: $29^{\text {th }}$ September, 2017

\section{Introduction}

Haemoglobinopathies are a complex group of red cell disorders, ${ }^{1}$ which constitute a major burden of genetic diseases ${ }^{2}$ and one of the major public health problems in India. ${ }^{1}$ Haemoglobinopathies have a highly variable clinical manifestations. ${ }^{3}$ At one end of the spectrum there is incompatibility with life and at the other, the patient under a stress, such as pregnancy, may experience some deterioration in her normal healthy state. Both the abnormal haemoglobin and the thalassaemia give rise to health problems of immense proportions. ${ }^{3}$

The haemoglobinopathies are autosomal recessive inherited disorders of haemoglobin synthesis (thalassaemia) or structure (sickle cell disorder) that are responsible for significant morbidity and mortality on a worldwide scale. ${ }^{1}$

Individuals with trait (carriers) are healthy and unaware of their carrier status unless specifically screened. If a couple both carry a clinically significant haemoglobinopathy trait there is a 1 in 4 chance with each pregnancy that their child will inherit a major haemoglobinopathy. ${ }^{4}$

The exact magnitude of the problem in India is still obscure. There is a genetic, ethnic and regional diversity of the haemoglobin variants as well as of the mutations in India which emphasizes to tackle the problem at a regional level. Most of the patients of haemoglobinopathies have a high morbidity rate, intercurrent infections being unusually common, suffer from high economic burden, terminate fatally in childhood, and have emotional and psychological trauma including the family members. ${ }^{5}$

The most effective approach to reduce the burden of the society is to reduce the incidence by implementation of a carrier screening programme. ${ }^{5}$ There is an urgent need for making the people aware of this lethal malady. Health 
education is an important component of the preventive genetic programmes. ${ }^{4}$

Thalassaemia and haemoglobinopathy, which are prevalent throughoutIndia is heritable, treatable, curable and preventable disorders. A joint venture of antenatal and inductive screening seems to be the most fruitful strategy for haemoglobinopathy in India. Hence initiating a preventive programme for these diseases is a necessity rather than an option. ${ }^{4}$

\section{Material and Methods}

The present study was carried out in a tertiary care hospital for a period of 2 years from 2008 to 2010. 500 Antenatal patients attending Obstetric-out patient department (OPD) for routine check-up were included in study. Antenatal care (ANC) patient with clinical suspicion of anaemia, attending the ANC clinics (Routine checkup) at OBGY Department were included in study group. Institutional Ethical committee clearance was taken. Blood was collected in ethylene diammine tetra acetic acid (EDTA) bulbs from the anticubital vein, with all aseptic precaution for different types of laboratory investigations. Complete blood counts (using Mythic18, Orphee SA counter) and smears stained by using Standardised Romanowsky stain, Leishman stain for peripheral blood smears and Brilliant cresyl blue stain for reticulocyte count of all the patients were studied. Further screening of patient was done by Solubility test, Sickling test and Alkali denaturation test. Finally a very standardized method to detect $\mathrm{HbA}_{2}$ and $\mathrm{HbF}$ and presence of some abnormal $\mathrm{Hb}$ was done by using an automated high performance liquid chromatography (HPLC) (using VARIANT ${ }^{\mathrm{TM}}$ of Biorad Company) to study sickle cell and $\beta$ thalassemia syndromes. This is known as $\beta$ Thalassemia short programme. A final correlation of Solubility test, Sickling test, Alkali denaturation test and evaluation of HPLC was done in detection of sickle cell disorders and thalassaemia in Antenatal cases.

\section{Observations}

Out of total 500 pregnant women, 20(4\%) women are having haemoglobinopathies, whereas rest 480 women have normal haemoglobins $(96 \%)$. Out of 20 cases, maximum number of cases i.e. $11(2.2 \%)$ were of $\beta-$ Thalassemia trait, followed by Sickle cell trait cases i.e. 06 (1.2\%). Other haemoglobinopathies are also found i.e. - sickle cell disease $1(0.2 \%)$, $\delta \beta$ Thalassemia case $1(1.2 \%)$, and double heterozygous $1(0.2 \%)$. [Table 1, Fig. 1]

Table 1: Distribution of all cases studied

\begin{tabular}{|l|l|c|c|}
\hline \multicolumn{2}{|c|}{ Case Distribution } & No. of cases & Percentage \\
\hline Normal Cases & NAD & 480 & $96 \%$ \\
\hline Affected Cases & B- Thalassemia trait & 11 & $2.2 \%$ \\
\cline { 2 - 4 } & Sickle cell trait & 06 & $1.2 \%$ \\
\cline { 2 - 4 } & Sickle cell disease & 01 & $0.2 \%$ \\
\cline { 2 - 4 } & $\delta \beta$ Thalassemia & 01 & $0.2 \%$ \\
\cline { 2 - 4 } & $\begin{array}{l}\text { Double } \\
\text { Heterozygous }\end{array}$ & 01 & $0.2 \%$ \\
\hline \multicolumn{2}{|c|}{ Total Cases } & 500 & $100 \%$ \\
\hline
\end{tabular}

Figure 1: Percentage distribution of affected cases (20 Cases)

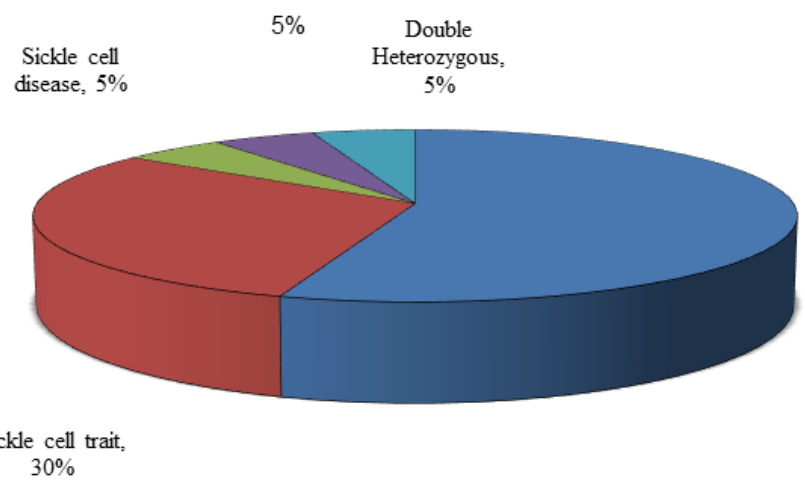

trait, $55 \%$ 
All the cases of $\beta$ - Thalassemia show $\mathrm{HbA}_{2}$ values $>3.5$. This can also be seen in double heterozygous case. The HbF values are increased, i.e. $>1$ in SCD, $\delta \beta$ Thalassemia and double heterozygous case. Whereas the abnormal $\mathrm{Hb}$ i.e. $\mathrm{HbS}$ is seen in SCT, SCD and double heterozygous. [Table 2] It is evident from the table that a statistically significant difference is noted for values of $\mathrm{HbA}_{2}$ in normal pregnant women and $\beta$ - Thalassemia trait cases. Also a statistically significant difference is noted for $\mathrm{HbS} / \mathrm{Abnormal} \mathrm{Hb}$ values in normal pregnant women and sickle cell trait cases. It is found that sickling test is showing positivity in all the cases of sickle cell trait, SCD and double heterozygous, with none of the cases showing false positivity. [Fig. 2, 3] However solubility test is showing false positivity in 4 cases, and AD test is showing false positivity in 1 case. [Table 3] Sickling test has highest sensitivity and specificity as compared to the solubility test and AD test.

Table 2: HPLC interpretation in affected cases

\begin{tabular}{|l|l|c|c|c|}
\hline \multicolumn{2}{|c|}{ Disease } & HbF & HbA $_{2}$ & Abnormal Hb \\
\hline \multicolumn{2}{|l|}{ Normal Pregnant women (480) } & $0.4 \pm 2.1$ & $3.0 \pm 0.5$ & $0.7 \pm 0.1$ \\
\hline \multirow{2}{*}{ Thalassemia trait(11) } & $($ mean \pm S.D) & $0.3 \pm 0.5$ & $5.4 \pm 0.4$ & $0.6 \pm 0.1$ \\
\cline { 2 - 5 } & P value & $>0.05$ & $<0.05^{*}$ & $>0.05$ \\
\hline \multirow{2}{*}{ Sickle cell trait (06) } & (mean+S.D) & $0.9 \pm 0.7$ & $3.3 \pm 0.4$ & $34.6 \pm 7.3$ \\
\cline { 2 - 5 } & P value & $>0.05$ & $>0.05$ & $<0.05^{*}$ \\
\hline \multicolumn{2}{|l|}{ Sickle cell disease (01) } & 12.9 & 2.8 & 80.5 \\
\hline$\delta \beta$ Thalassemia (01) & 11.3 & 2.8 & 0 \\
\hline \multicolumn{2}{|l|}{ Double Heterozygous (01) } & 18.7 & 3.9 & 48.2 \\
\hline
\end{tabular}

* - Statistically significant

Figure 2: (a) b thalassemia trait; (b) Sickle cell disease

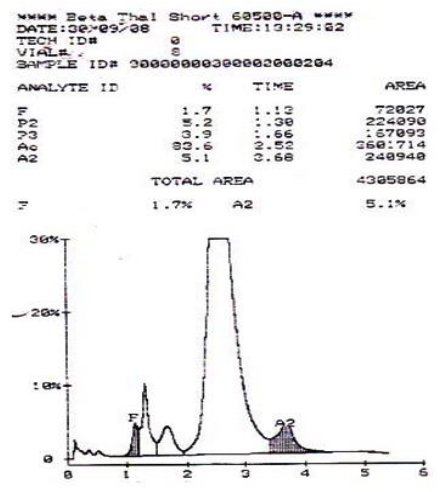

Beta Thalassemia Trait

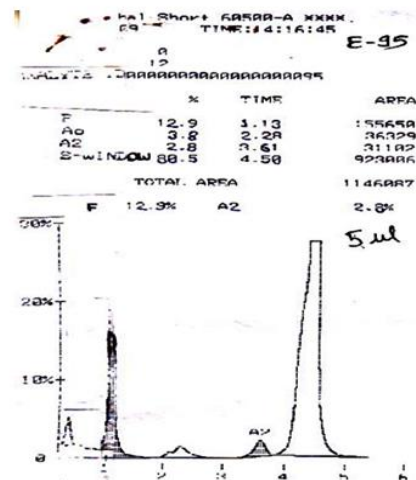

Sickle Cell Disease

Figure 3: (a) Delta beta thalassemia; (b) Double heterozygous
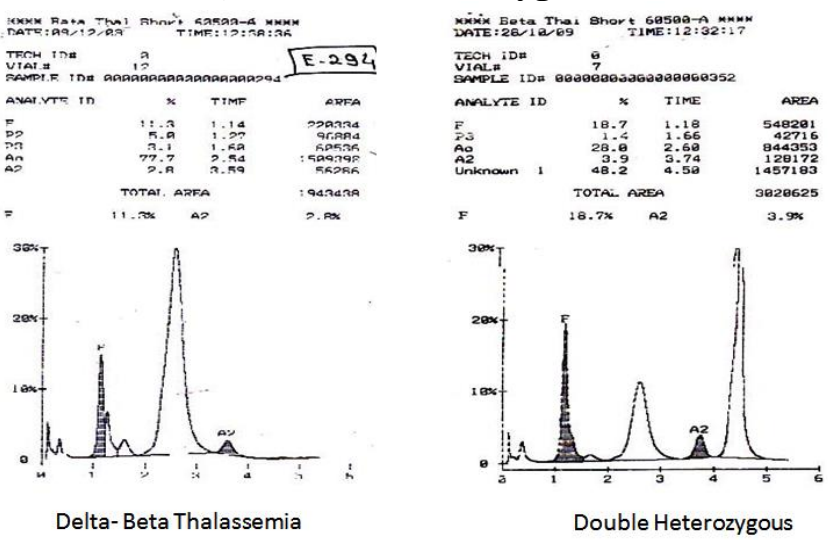
Table 3: Test results of different screening tests

\begin{tabular}{|l|c|c|c|}
\hline \multicolumn{1}{|c|}{ Results } & Solubility test & Sickling test & AD /FF test \\
\hline True Positive & 9 & 8 & 5 \\
\hline True Negative & 487 & 492 & 494 \\
\hline False Positive & 4 & Nil & 1 \\
\hline Sensitivity & $69.20 \%$ & $100 \%$ & $83.33 \%$ \\
\hline Specificity & $100 \%$ & $100 \%$ & 99.79 \\
\hline
\end{tabular}

Out of total 20 positive pregnant women only partners of 8 women were screened. Rest of the 12 partners was either not traceable or not ready to get screened. Out of total 8 partners screened, 3 (37.5\%) partners are found positive. 1 screened positive for SCT and other 2 for $\beta$ - Thalassemia trait. Thus 3 out of 8 couples screened are at risk of having children with haemoglobinopathies. [Table 4]

Table 4: Results for partner screening

\begin{tabular}{|l|c|c|}
\hline \multicolumn{1}{|c|}{ Result } & No. of cases & Total \\
\hline Positive & $\begin{array}{c}\text { 1(SCT) }+ \\
\text { (Thal-trait) }\end{array}$ & 3 \\
\hline Negative & 5 & 5 \\
\hline Total & & 8 \\
\hline
\end{tabular}

\section{Discussion}

The prevalence of haemoglobinopathies in present study was found to be $4 \%$. WHO (World Health Organization) estimates that $5 \%$ of adults are carriers with $3.9 \% \beta$-Thal and $2.3 \%$ SCD. ${ }^{6}$ Thus, prevalence rate of haemoglobinopathies in present study correlates well with study by Rowley et.al. ${ }^{7}$ Health technology assessment in England ${ }^{8}$, Al-Allawi ${ }^{9}$ et.al. The prevalence of $\beta$-Thal trait in present study is $2.2 \%$ which is in accordance with study by Gupta ${ }^{10}$ et. al and Panda ${ }^{11}$ et.al. However a little higher prevalence is found in Al-Allawi ${ }^{9}$ et al andSachdev ${ }^{12}$ et al studies as compared to present study. The prevalence of Sickle cell trait in present study matches that with Al-Allawi ${ }^{9}$ et al study i.e. $1.2 \%$. However in all other studies the SCT prevalence is much higher than present study. The prevalence of Sickle Cell Disease in present study correlates well with Gupta ${ }^{10}$ et al study. According to Census 2001 the expected sufferers of sickle cell gene i.e. sickle cell disease is $0.5 \%$. Thus these values correlate well with present study. Prevalence of $\delta \beta$-thal correlates well with Al-Allawi ${ }^{9}$ et al study. No reference regarding studies for double heterozygous in pregnant women are found. Studies are done by various authors in double heterozygous, in general population. Mittal et al recorded a high incidence of double heterozygous i.e. 3-7\%. ${ }^{5}$ The routine diagnostic test is Hb HPLC: these will demonstrate increase in $\mathrm{HbA}_{2}$ (i.e., $>3.5 \%$ of total hemoglobin) and usually $\mathrm{HbF}$ (i.e., $>1 \%$ ). In the right clinical and ethnic context, an elevated $\mathrm{HbA}_{2}$ is considered diagnostic of $\beta$-thalassemia trait. ${ }^{12}$ [Table V] Thus the elevated level of $\mathrm{HbA}_{2}$ is diagnostic of $\beta$-thalassemia trait also elevated levels of $\mathrm{HbA}_{2}$ in present study matches well with other studies. Also a statistically significant difference is noted for values of $\mathrm{HbA}_{2}$ in normal pregnant women and $\beta$-Thalassemia trait cases, in present study. [Table 5]

Table 5: Comparative Study of values of $\mathrm{HbF}, \mathrm{HbA}_{2}$ and $\mathrm{HbS}$ in various haemoglobinopathies.

\begin{tabular}{|l|c|c|c|c|}
\hline & & R.S.Balgir $^{5}$ & $\begin{array}{c}\text { Amrita } \\
\text { panda et.al. }\end{array}{ }^{13}$ & Present Study \\
\hline \multirow{3}{*}{-thal trait } & $\mathrm{HbF}$ & $1-5$ & 0.6 & 0.3 \\
\cline { 2 - 5 } & $\mathrm{HbA}_{2}$ & $3.5-7.0$ & 4.5 & 5.4 \\
\hline \multirow{4}{*}{ Sickle Cell trait } & $\mathrm{HbF}$ & $\mathrm{N}$ & 0.8 & 0.9 \\
\cline { 2 - 5 } & $\mathrm{HbA}_{2}$ & $2-4$ & 1.75 & 3.3 \\
\cline { 2 - 5 } & $\mathrm{HbS}$ & $38-45$ & 25.22 & 34.6 \\
\hline \multirow{3}{*}{$\begin{array}{c}\text { Sickle Cell } \\
\text { Disease }\end{array}$} & $\mathrm{HbF}$ & $1-20$ & - & 12.9 \\
\cline { 2 - 5 } & $\mathrm{HbA}_{2}$ & $2-4$ & - & 2.8 \\
\cline { 2 - 5 } & $\mathrm{HbS}$ & $75-95$ & - & 80.5 \\
\hline \multirow{2}{*}{$\begin{array}{l}\text { Double } \\
\text { Heterozygous }\end{array}$} & $\mathrm{HbF}$ & $5-30$ & - & 18.7 \\
\cline { 2 - 5 } & $\mathrm{HbA}_{2}$ & $4-8$ & - & 3.9 \\
\cline { 2 - 5 } & $\mathrm{HbS}$ & $60-85$ & - & 48.2 \\
\hline
\end{tabular}


Comparative Study for values of $\mathrm{HbF}, \mathrm{HbA}_{2}$ and $\mathrm{HbSin} \beta$-thal trait, sickle cell trait, sickle cell disease and double heterozygous matches very well with the reference values. [Table 5]

It is evident from present study that a difference is noted for $\mathrm{HbS} / \mathrm{Abnormal} \mathrm{Hb}$ values in normal pregnant women and Sickle cell trait/disease cases. In addition to $\mathrm{HbS}, \mathrm{HbF}$ values are also significantly raised in Sickle cell disease. Hence significantly raised $\mathrm{HbS}$ can be reliably used to diagnose cases of Sickle cell trait cases while raised $\mathrm{HbS}$ and $\mathrm{HbF}$ can be reliably used to diagnose cases of Sickle cell disease cases in pregnancy.

In Double Heterozygous casesignificant difference is noted for all the Hb HPLC values as compared to normal pregnant women. Hence these values can be reliably used to diagnose cases of Double Heterozygous in pregnancy.

No comparative studies for values of $\mathrm{HbF}$, $\mathrm{HbA}_{2}$ and $\mathrm{HbSfor} \delta \beta$-Thal in pregnant women are found so far. However, difference is noted for HbFvalues among $\delta \beta$-Thal case in pregnant women. Sickling test had highest sensitivity and specificity of $65 \%$ and $95 \%$ respectively compared with solubility test which had sensitivity and specificity of $45 \%$ and $90 \%$ respectively according to study by Andrew LivexOkwi $^{13}$ et al. Overall sensitivity and specificity of solubility test was found to be $93.8 \%$ and $100 \%$ respectively with positive predictive value of $100 \%$ and negative predictive value of $97.4 \%$ according to study by Mukherjee ${ }^{14}$ et.al.

In the present study it was found that sickling had $100 \%$ sensitivity and specificity as compared to solubility test which has $69.2 \%$ sensitivity and $100 \%$ specificity. Present study correlates well with above studies. In over two million automated HPLC screening tests carried out in California between 1990 and 1993, only 1 false positive and 1 false negative test have been recorded (unpublished report). ${ }^{15}$

A recent study across nine US laboratories, using automated HPLC (Bio-Rad) and the same standard operating procedures for the State of California Neonatal Screening Programme, has reported a specificity of $99 \%$, while the same programme has reported, to members of the US Guideline Panel, a sensitivity of over $99.9 \%$ for the technique. Present evidence and experience suggest that HPLC have acceptable sensitivity and specificity when properly used. ${ }^{1}$ Study by Sachdevaet al $^{12}$ states that cation exchange HPLC is a convenient, efficient, reproducible \& cost effective method for screening $\&$ diagnosis of Thalassemia \& other haemoglobinopathies.
As compared to above studies, in present study it was found that HPLC is emerging as the most advance technique in diagnosis of Haemoglobinopathies, with acceptable sensitivity and specificity. Also a very convenient, efficient and reproducible method. ${ }^{12}$ Screening for hemoglobinopathy was done in which $55 \%$ partners were tested. 77 partners at risk were identified out of $810 .{ }^{16} 3$ out of 591 couples were at risk of having child with hemoglobinopathy like Thal major/intermedia or $5 / 1000 .{ }^{9}$ If black women has sickle cell trait and her partner is black, 1:40 chances that she will have a child with sickle cell disorder more commonly SCA, SCD, delta-beta $\delta \beta-$ Thal. ${ }^{17}$ In present study 3 out of 8 partners were tested for hemoglobinopathy that is $37.5 \%$ partners were positive. Hence highly significant.

\section{Conclusion}

Using HPLC method in screening for Thalassemia and sickle cell disorder in pregnant women in the region support the notion of establishing a preventive and control program of this common genetic disorder. Detection of carrier status during pregnancy along with couple screening provides prospective parents with the option of testing the fetus for a hemoglobinopathy. This will give parents the opportunity of planning a family without disease, also alleviating the health burden to society. A joint venture of antenatal and high risk couple screening seems to be the most fruitful strategy for control of haemoglobinopathy in India.

\section{References}

1. Johnston TA. Haemoglobinopathies in pregnancy. The Obstetrician \&Gynaecologist2005;7:149-57.

2. Sinha S, Kumar A, Gupta V, Kumar S, Singh VP, Raman R Sachdeva A, Kumar S, Sood SK, Gupta A. Haemoglobinopathies - thalassaemias and abnormal haemoglobins in eastern Uttar Pradesh and adjoining districts of neighbouring states. Current Science 2004 September 25;87(6):77580.

3. Huntsman RG. Haemoglobinopathies in pregnancy. J clin Path 29, Suppl (Roy Coll Path) 10:42-53.

4. Huissman THJ, Carver MFH, Efremov GD. A Syllabus of Human Hemoglobin Variants. Atlanta GA: The Sickle Cell Anemia Foundation;1996.

5. Balgir RS. Control and prevention of the genetic load of haemoglobinopathies in India. Natl Med J India 1999;12:234-8.

6. Genetics in Family Medicine: The Australian Handbook for General Practitioners Haemoglobinopathies: 2007. Accessed online at http://www.gpgenetics.edu.au 
7. Rowley PT, Loader S, Walden ME. Toward providing parents the option of avoiding the birth of the first child with Cooley's anemia: response to hemoglobinopathy screening and counseling during pregnancy. Ann NY AcadSci 1986;445:408-16.

8. Davies SC, Cronin E, Gill M, Greengross P, Hickman M, Normand C. Screening for sickle cell disease and thalassaemia: A systematic reviewwith supplementary research. Health Technology Assessment (Winchester,England) 2000;4:1-99.

9. Allawi NA, Al-Dousk AA. Frequency of haemoglobinopathies at premarital health screening in Dohuk, Iraq: implications for a regional prevention programme. Eastern Mediterranean Health Journal (EMHJ) 2010;16:381-5.

10. Gupta RB, Mohanthy D. Community control programme of haemoglobinopathies. Genetic Studies; RMRCT. Annual Report 2003-04.

11. Panda A, Praveen B, Bisht SS. Clinical and pathological status of haemoglobinopathies among pregnant women in southern Orissa. Indian Journal of Biotechnology 2009 October 8;8:456-7.

12. Sachdeva A, Kumar S, Sood SK, Gupta A. High performance liquid chromatography (HPLC) in the diagnosis of thalassemia and other haemoglobinopathies in India. In: The $44^{\text {th }}$ American Society of Hematology Annual Meeting; Detroit, USA: The American society of hematology annually, 2002.

13. Okwi LA, Ocaido M, Byarugaba W, NdugwaCM, Parkes A. Solubility tests and the peripheral blood film method for screening for sickle-cell disease: a cost benefit analysis. .S Afr Med J. 2009 Dec 7;99:887-91.

14. Mukherjee MB, Nadkarni AH, Gorakshakar AC, Ghosh K, Mohanty D, Colah RB. Clinical, hematologic and molecular variability of sickle cell- $\beta$ thalassemia in western India. Indian J Hum Genet 2010;16:154-8.

15. Goldbloom RB. Screening for Hemoglobinopathies in Canada.U.S. Preventive Services Task Force, Chapter 20:206-18.

16. Screening for Hemoglobinopathies. Congenital Disorders. Guide to clinical Preventive Services. $2^{\text {nd }}$ ed. 1996.

17. Bowman JE. Prenatal Screening for Hemoglobinopathies. Am J Hum Genet 1991;48:433-8. 